\title{
Influence of Small Amphiphiles on Aqueous Dispersions of $\beta$-Lactoglobulin A and Bovine Serum Albumin: (2) Surface Energy and Emulsifying Properties
}

\author{
Zahur Z. Haque ${ }^{*}$, Guichard L. Bohoua ${ }^{2}$ \\ ${ }^{1}$ Department of Food Science, Nutrition and Health Promotion, Mississippi State University, Starkville, USA \\ ${ }^{2}$ Ecole des Sciences de la Nature Centre, Universitaire d'Abobo Adjame Abidjan, Abidjan, Cote d'Ivoire \\ Email: ${ }^{*}$ hh5@msstate.edu
}

Received 12 June 2015; accepted 21 September 2015; published 24 September 2015

Copyright $\odot 2015$ by authors and Scientific Research Publishing Inc.

This work is licensed under the Creative Commons Attribution International License (CC BY).

http://creativecommons.org/licenses/by/4.0/

(c) (i) Open Access

\begin{abstract}
Influence of amphiphiles on surface energy $(\gamma)$, emulsifying activity index (EAI) and emulsion stability (ES) of fatty-acid free bovine serum albumin (FAF-BSA), bovine serum albumin (BSA), and $\beta$-lactoglobulin A ( $\beta$-LGA) was studied. Contact angle measurements $(\theta)$ of sessile drops of proteinsurfactant mixtures were determined using water and $\alpha$-bromonaphthalene as solvents of known parameters to calculate $\gamma$. All surfactants except zwitterionic Z8 increased $\gamma$. The greatest increase was by anionic SDS. All surfactants significantly reduced EAI in spite of increased $\gamma$. ES was reduced by all surfactants except cationic TDTM which, conversely, enhanced ES by up to $186 \%$ for BSA and $\beta$-LGA.
\end{abstract}

\section{Keywords}

Functionality, Emulsion, Surface Energy, Interface, Stability, Surfactant

\section{Introduction}

Emulsification property is an important functionality that impacts acceptability of various value added foods [1]. Food proteins in general are excellent emulsifiers because of their amphipathic nature [2]. However, food emulsions are complicated systems with food proteins, peptides, food emulsifiers (e.g., lecithin, triglyceride etc.) and

\footnotetext{
${ }^{*}$ Corresponding author.
} 
stabilizers (e.g., gums). Small amphiphiles affect surface activity of proteins differently. Numerous investigations have reported competitive binging of small amphiphiles and displacement of proteins from interfaces [3] [4]. Amphiphiles vary in their role related to this phenomenon of protein displacement in the interface.

Liquid-solid contact angle of an amphiphile containing dispersion on a uniformly hydrophobized planer surface is a reflection of the surface energy [5], amphipathicity [6] and concentration [7] of the amphiphile used. In a related study, it was observed that hydrophobic peptide fractions in enzyme hydrolyzed whey significantly increased liquid-solid contact angle $(\theta)$, i.e., reduced surface activity, of $\kappa$-casein and $\beta$-lactoglobulin $\mathrm{AB}$ as a function of the surface hydrophobicity of the peptide fraction [8].

The previous paper in this series investigated the contribution of various amphiphiles on short range $(\mathrm{H}-$ bonding) and Lifshitz Van der Waals long range interactions (hydrophobic interactions) in protein dispersionsrevealed that the smallest peptide-like zwitterionic surfactant used, N-octyl-N, N-dimethyl-3-ammonio-1-propanesulfonate, contributed most to water structuring via H-bonding [9]. This part of the study investigates the influence of the same set of cationic, anionic, nonionic and peptide-like straight chain and aromatic zwitterionic amphiphiles on surface energy $(\gamma)$ and emulsifying properties of the same proteins that are primary contributors to whey protein functionality [10] [11]; $\beta$-lactoglobulin (variant A) ( $\beta$-LGA) and bovine serum albumin (BSA). In this study, fatty acid free BSA (FAF-BSA) was used to determine the effect of delipidation.

\section{Materials and Methods}

\subsection{Materials}

All materials and their sources were as listed in the previous article in this series [9]. Commercially available peanut oil was used for preparation of emulsions.

\subsection{Methods}

Protein dispersions. Proteins were dispersed (final concentration 1\%, w/v) by vortexing in double glass distilled water or $\alpha-\mathrm{BrN}$ at $22^{\circ} \mathrm{C}$. Surfactant were added to aliquots of the protein dispersions to obtain desired surfactant concentrations of 0 (nil) (control), $1 \%, 2 \%$, and $4 \%$ (w/w).

Emulsifying Properties. Emulsion activity index (EAI) and emulsion stability (ES) proteins were determined as described before [12]. Proteins were dispersed $(0.8 \mathrm{ml})$ in $10 \mathrm{mM}$ imidazole buffer $(\mathrm{pH} 7.0)$ and $0.2 \mathrm{~mL}$ commercially available peanut oil was added. The emulsion was prepared by sonication at $4^{\circ} \mathrm{C}$ for $20 \mathrm{sec}$, at $20 \%$ of total power of $150 \mathrm{~W}$ (RMS), in a Vibra-cell (Sonics and Materials Inc. Danbury, CT). Emulsion $(10 \mu \mathrm{L})$ was suspended in $10 \mathrm{~mL}$ of $10 \mathrm{mM}$ imidazole buffer containing $0.1 \%$ SDS, pH 7.0 and absorbance was determined at $600 \mathrm{~nm}$ for EAI. The EAI was expressed as $\mathrm{m}^{2}$ surface area created per $\mathrm{g}$ of protein as described earlier [12],

$$
\mathrm{EAI}=\frac{2(2.203) A \Theta C}{L} \mathrm{~m}^{2} / \mathrm{g}
$$

where, $L$ was the cell-path in cuvette, $\Theta$ was the dispersed phase (oil) fraction, $A$ was the absorbance at $600 \mathrm{~nm}$, and $C$ was the protein concentration $(\mathrm{mg} / \mathrm{mL})$. Results represent mean of three experiments.

Emulsion stability (ES) was determined after centrifugation of the emulsion $(1 \mathrm{~mL})$ using a Millipore personal centrifuge at $3200 \times \mathrm{G}$ for $30 \mathrm{~min}$. Using a fine syringe, the drained portion was removed; ES was calculated as a percentile measure of remaining emulsion. Different concentrations of various amphiphiles were mixed with the proteins and EAI and ES were determined immediately.

Determination of contact angle. The contact angle $(\theta)$ was determined on hydrophobized glass surface as described in anearlier paper [6]. Hydrophobized (silinated) glass covers were used as planner surface to measure $\theta-\mathrm{H}_{2} \mathrm{O}$ and $\theta-\alpha-\mathrm{BrN}$ data of the sessile droplet of surfactant-protein mixtures. At least three readings were recorded and means were tabulated. [13],

Surface energy of protein samples. The surface energy $(\gamma)$ was calculated using the extended Young equation

$$
1+\operatorname{COS} \theta=\left(2 / Y_{L}^{T O T}\right)\left[\left(Y_{L}^{L W} X Y_{P}^{L W}\right)^{1 / 2}+\left(Y_{L}^{S R} X Y_{P}^{S R}\right)^{1 / 2}\right]
$$

where, $\theta$ represents the contact angle, $Y_{L}$ and $Y_{P}$ are, respectively, $\gamma$ of the liquid used for $\theta$ measurements, and $\gamma$ of the protein layer. $L W$ and $S R$ correspond, respectively, to the Lifshitz-Van der Waals and short range hydro- 
gen bonding components, while TOT refers to the sum of both contributions.

The two standard liquids used were pure water and $\mathrm{BrN}$. When $\alpha-\mathrm{BrN}$ is used as solvent, molecules do not interact with each other via hydrogen bonds to any significant degree. As a result, $S E$ does not include the $S R$ contribution [13]. For water, $Y^{S R}=5.10 \mathrm{~mJ} \cdot \mathrm{m}^{-2}, Y^{L W}=21.8 \mathrm{~mJ} \cdot \mathrm{m}^{-2}$ and $Y^{T O T}=72.8 \mathrm{~mJ} \cdot \mathrm{m}^{2}$ for $\alpha-\mathrm{BrN}, Y^{S R}=0.8$ $\mathrm{mJ} \cdot \mathrm{m}^{-2}, Y^{L W}=Y^{T O T}=44.4 \mathrm{~mJ} \cdot \mathrm{m}^{-2}$. Thus, with the $\theta$ measured with two liquids of known $Y^{S R}$ and $Y^{L W}$ and using Equation (2) twice, we obtained two equations with two unknowns, from which $Y^{S R}$ and $Y^{L W}$ was derived [13] [14].

Statistical analysis: A completely randomized design with three replications was utilized to evaluate the effect of the surfactants and their concentration on $\gamma$, EAI and ES. Three samples were taken per replication for each treatment. The data were analyzed using the general linear models (PROCGLM) procedure. The means were separated using Fisher's protected least significance test at $(\mathrm{p}<0.05)$ [15]. The statistical analysis was conducted with SAS version 8.1 [16] [17].

Abbreviations: All abbreviations are the same as those give in the first paper in this series [7].

\section{Results and Discussion}

Surface energy: The surface energy $(\gamma)$ of FAF-BSA dispersions was significantly increased by all surfactants except Z8 and CHAPS. At 1\% (w/w) of surfactant usage level, Tx100, Z8 and increased $\gamma$ by $19 \%, 3 \%$ and $10 \%$, respectively (Figure 1). The premise that increased $\gamma$ has entropic origin due to structural constraint of water

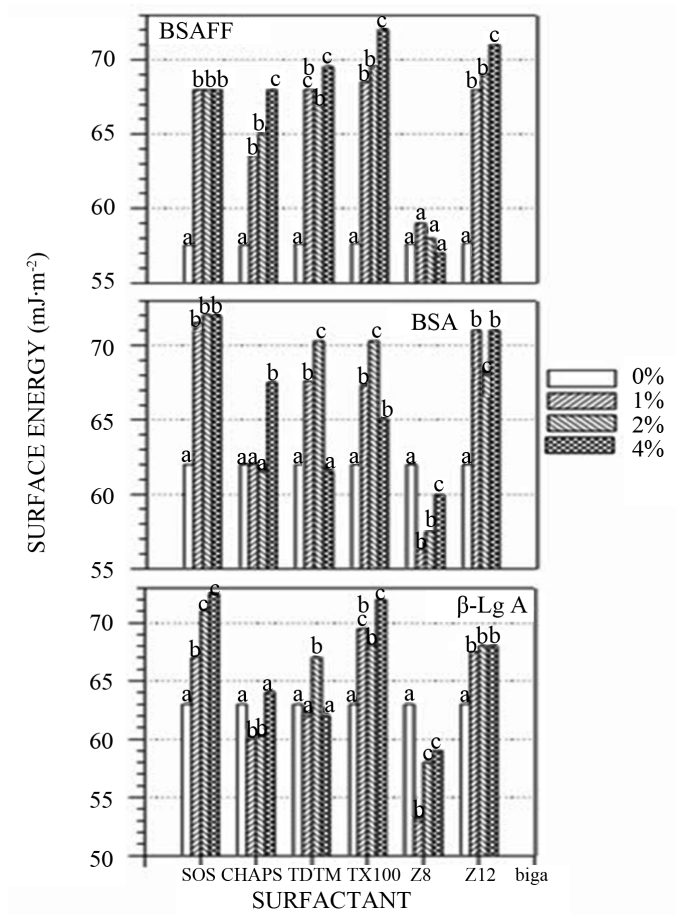

Figure 1. The surface energy of proteins dispersions with and without surfactants on hydrophobized planner solid surface. Abbreviations are as follows: BSAFF is fatty acid free bovine serum albumin, BSA is bovine serum albumin, $\beta$ LGA is $\beta$-lactoglobulin A, SDS is sodium dodecyl sulfate, TDTM is tetradodecyltrimethyl ammonium bromide, Z8 is $\mathrm{N}$-octyl-N,N-dimethyl-3-ammonio-1-propanesulfonate, Z12 is $\mathrm{N}$-dodecyl-N,N-dimethyl-3-ammonio-1-propanesulfonate, TX100 is Triton X-100, and CHAPS is 3[(3 cholaminodopropyl) dimethyl ammonio]-1 propane sulfonate. Dissimilar letters atop the bars denote significant difference. The percentages in the legend represent percentage of surfactant used (w/w protein). 
molecules is theoretically sound [18]. This potential energy is decreased by expulsion of the disruptive molecules out of bulk water into the interface [19]. Thus, increase in $\gamma$ is directly proportional to the disruptive particles' enhanced surface activity or affinity for the apolar phase; air, liquid or solid. Zwitterions, Z8 and CHAPS, have the same head group. However, their hydrophobic moiety are different; Z8 is smaller (280 compared to 615 Dalton) with a straight chain octyl-chain whereas CHAPS has a myristoyl-chain with a bile-salt-like aromatic moiety attached to it. As seen earlier, the contribution of short-range interaction in the FAF-BSA dispersion (via H-bonding) was the highest for Z8 followed by CHAPS [9] and this indicated increased structuring of water [20].

In BSA dispersions, $\gamma$ of control was higher than for FAF-BSA (62 compared to $55.5 \mathrm{~mJ} \cdot \mathrm{m}^{2}$ ). The $\gamma$ of the BSA was conceivably higherdue to the attached fatty acids that would cause increase in surface hydrophobicity [21]. Here again, $\gamma$ was increased by all amphiphiles except Z8 at all concentrations and CHAPS at 1 and 2\% (w/w protein) (Figure 1). At 1\% (w/w) surfactant level, Z8 actually decreased $\gamma$ by $9 \%$. The increased $\gamma$ by the other surfactants implied protein unfolding causing exposure of hydrophobic amino acid residues [13]. This trend was more evident in FAF-BSA indicating significant change in interaction of protein and small amphiphiles merely due to delipidation. Based on Differential Scanning Calorimetry, it was reported that FAF-BSA is less stable than BSA [22]. Surfactant effects on $\beta$-LGA dispersions were similar to those of FAF-BSA and BSA. Again, Z8 was the least perturbing of water structure and SDS the most (Figure 1).

Emulsifying properties: The EAI of control proteins was high and in the following order: BSA $\left(400 \mathrm{~m}^{2} / \mathrm{g}\right)>$ FAF-BSA $\left(225 \mathrm{~m}^{2} / \mathrm{g}\right)>\beta$-LGA $\left(220 \mathrm{~m}^{2} / \mathrm{g}\right)$. Removal of fatty acids from BSA to produce FAF-BSA decreased EAI by approximately $45 \%$. In BSA and FAF-BSA, highest reduction in EAI was by SDS and least was by TDTM (Figure 2). These two amphiphiles have straight chain alkyl groups of approximately the same size

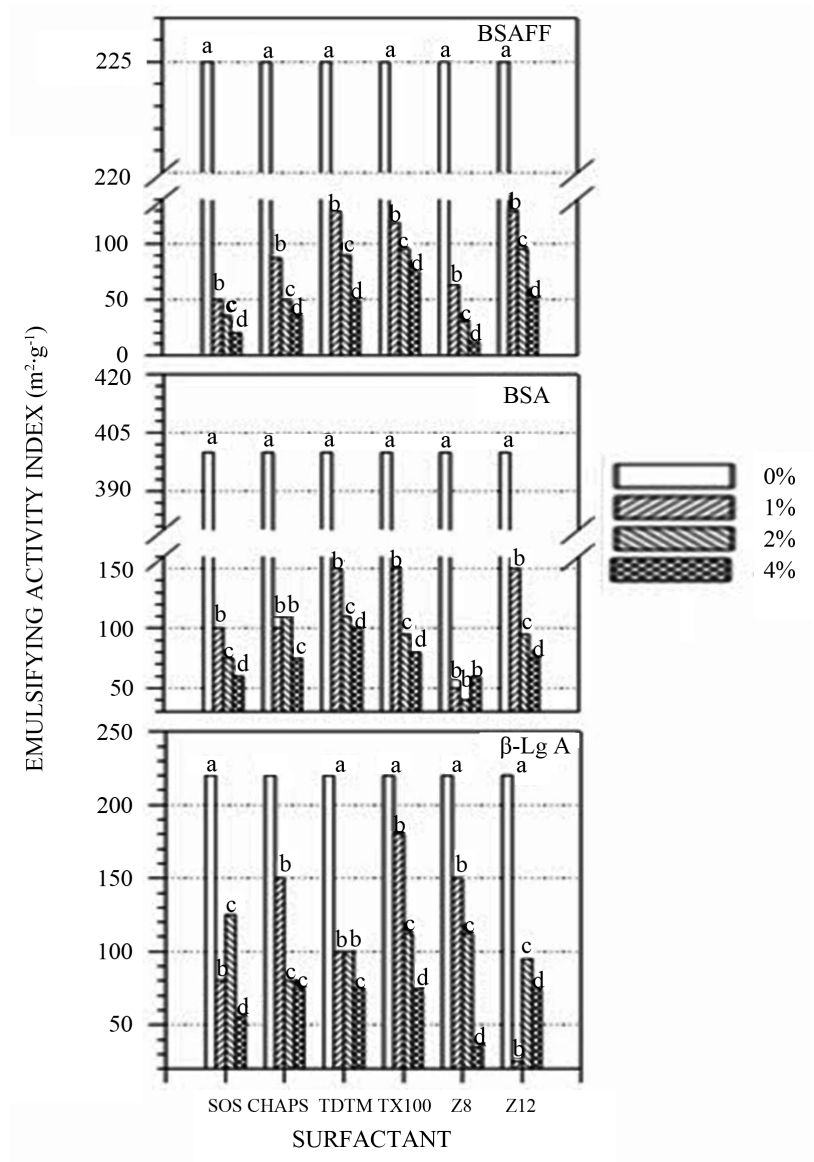

Figure 2. The emulsifying activity index of the various protein dispersions with and without surfactants. All abbreviations and statistical notations are the same as those given in the legend for Figure 1. 
(SDS = 12; TDTM = 14) but have opposite head group charge; SDS is negatively charged whereas TDTM ispositively charged. Note that SDS caused greatest increase in $\gamma$ for BSA and one of the highest for FAF-BSA (Figure 1). In case of $\beta$-LGA, greatest reduction in EAI was caused by nonionic TX100, and lowest was by straight chain zwitterionic Z12. Data show that decreased $\gamma$ in the presence of the surfactants did not cause an increase in amount of surface created per unit mass of protein plus surfactant mixture. Therefore, the premise that increase surface activity leads to improved functionality is not valid in this case. This is conceivably due to the competitive surfactant binding to the interface and protein displacement effect [4].

The trends of the various amphiphiles showed heterogeneity in overall behavior due to differences in their structure and orientation. Each amphiphile had its intrinsic characteristic such as its efficiency and its effectiveness. Effectiveness is maximum concentration at which the amphiphile can accumulate at an interface and is related to interfacial area occupied by the amphiphile molecule (inversely related to effectiveness). Effectiveness of adsorption, therefore, depends on structural groupings in the amphiphile molecule and its orientation at the interface [23].

Interestingly, unlike their influence on FAF-BSA and BSA, amphiphiles had a totally different effect on the EAI of $\beta$-LGA. Even though BSA and $\beta$-LGA are both globular in their shape, they differ in their molecular weight; $\beta$-LGA is much smaller (18.3 vs. $67 \mathrm{kDa}$ ). The type of adsorbed protein can affect the nature of van der Waals attractive force between emulsion droplets [24]. In oil-in-water emulsions, the major contenders for balancing repulsive forces are double layers and steric interaction between protein layers. However, with large protein molecules steric effects are likely to be predominant [24]. Differences in protein flexibility and hydrophobicity could also account for the difference in the emulsifying activity in the presence of the amphiphiles.

\section{Emulsifying Stability (ES)}

In FAF-BSA dispersions, TDTM had no effect on ES whereas all other surfactants decreased ES significantly by $70 \%-75 \%$ regardless of the concentration of the surfactant used (Figure 3). In case of BSA, ES was low even

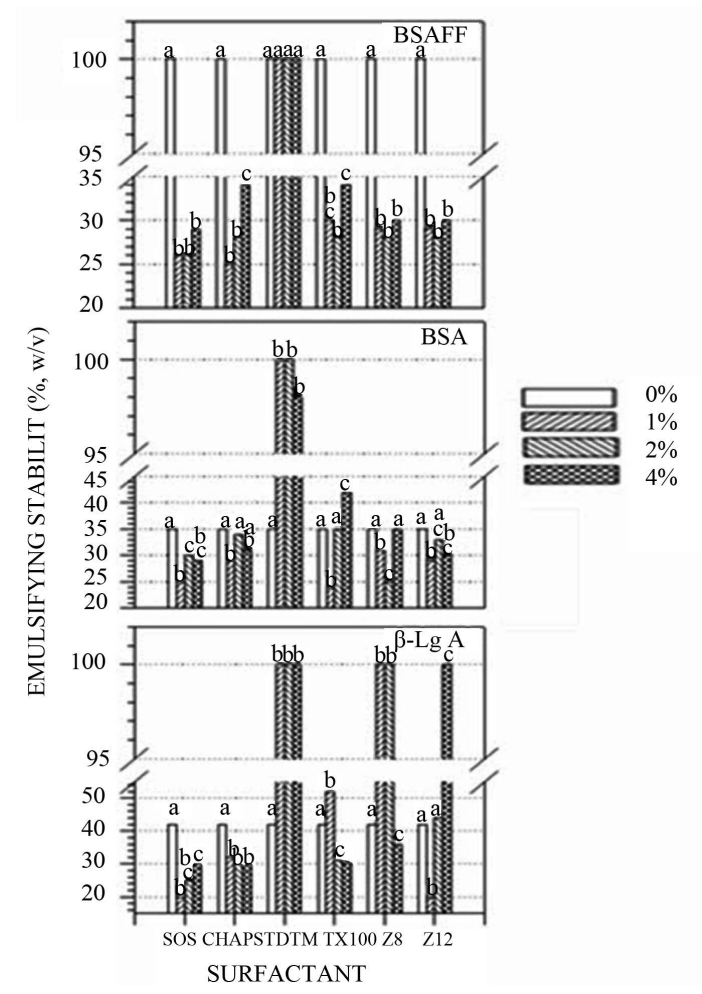

Figure 3. The emulsion stability of the various protein dispersions with and without surfactants. All abbreviations and statistical notations are the same as those given in the figure legend for Figure 1. 
for the nil control and all surfactants except TDTM decreased it further. TDTM dramatically increased ES by $185 \%$ at 1 and $2 \%(\mathrm{w} / \mathrm{w})$ surfactant usage levels. ES data for $\beta$-LGA were different compared to the other proteins (Figure 3). Similar to the observation related to BSA, TDTM enhanced stability of the interface by $138 \%$ regardless of the concentration used, while Z8 increased ES at $1 \%$ to $2 \%(\mathrm{w} / \mathrm{w})$, and Z12 only at $4 \%(\mathrm{w} / \mathrm{w})$ of surfactant usage level (Figure 3).

The improvement of ES by TDTM may be due to the intrinsic steric properties of TDTM. The essence of a good steric stabilizer is that it should be strongly attached to the surface, but it should also protrude significantly into the continuous phase in order to form a polymeric layer of appreciable thickness [25]. Increase in potential energy of the particles at the stern layer could also contribute to the marked improvement in the ES.

\section{Conclusion}

In conclusion, all amphiphiles except Z8 increased $\gamma$. However, this did not lead to increased EAI indicating that factors other than $\gamma$, such as protein-protein association and molecular flexibility, are critical during emulsion making [26]. Stability of emulsions was dramatically improved by TDTM in $\beta$-LGA and BSA and unaffected by it in FAF-BSA perhaps reflected tenacious protein-amphiphile binding leading to improved positioning and self association though adhesive contact between hydrophobic tail groups at the oil-water interface.

\section{Acknowledgements}

Approved as journal article \# 12696 of the Mississippi Agricultural and Forestry Experiment Station, Mississippi State University, MS 39762. Research was completed as part of the Miss. Agric. \& For. Exp. Sta. Project No. MIS 352021. Funding was also from USDA ARS Mississippi Center for Food Safety and Post-Harvest Technology (SCA 58-6402-7-230). No. MIS 352021.

\section{References}

[1] Phillips, L.G., Whitehead, D.M. and Kinsella, J.E. (1994) Structure-Function Properties of Food Proteins. Academic Press, San Diego. http://www.worldcat.org/title/structure-function-properties-of-food-proteins/oclc/30436068

[2] Walstra, P. and van Vliet, T. (2003) Chapter II Functional Properties. Progress in Biotechnology, 23, 9-30. http://dx.doi.org/10.1016/S0921-0423(03)80002-3

[3] Euston, S.E., Singh, H., Munro, P.A. and Dalgleish, D.G. (1995) Competitive Adsorption between Sodium Caseinate and Oil-Soluble and Water-Soluble Surfactants in Oil-in-Water Emulsions. Journal of Food Science, 60, 1124-1131. http://dx.doi.org/10.1111/j.1365-2621.1995.tb06307.x

[4] Dickinson, E., Iveson, G. and Tanai, S. (1993) Competitive Adsorption in Protein-Stabilized Emulsions Containing Oil-Soluble and Water-Soluble Surfactants. Special Publication-Royal Society of Chemistry, 113, 312-322.

[5] Mohan, C.O., Ravishankar, C.N. and Srinivasagopal, T.K. (2008) Effect of $\mathrm{O}_{2}$ Scavenger on the Shelf-Life of Catfish (Pangasius sutchi) Steaks during Chilled Storage. Journal of the Science of Food and Agriculture, 88, 442-448. http://dx.doi.org/10.1002/jsfa.3105

[6] Bohoua, G.L. and Haque, Z.U. (2007) Surface Activity of Surfactants and Dairy Proteins. Milchwissenschaft, 62, 394397.

[7] Haque, Z.U., Shon, J. and Williams, J.B. (2009) Efficacy of Sour Whey as a Shelf-Life Enhancer: Use in Antioxidative Edible Coatings of Beef Steak. Journal of Food Quality, 32, 381-397. http://dx.doi.org/10.1111/j.1745-4557.2009.00255.x

[8] Haque, Z.U., Bohoua, G.L., Williams, B. and Mikel, W.B. (2010) Influence of Whey Peptides on the Surface Activity of $\kappa$-Casein and $\beta$-Lactoglobulin A. International Journal of Dairy Technology, 63, 190-196.

[9] Haque, Z.Z. and Bohoua, G.L. (2015) Influence of Small Amphiphiles on Aqueous Dispersions of $\beta$-Lactoglobulin A and Bovine Serum Albumin: (1) Intermolecular Interactions. Food and Nutrition Sciences, 6.

[10] Kinsella, J.E. and Whitehead, D.M. (1989) Proteins in Whey: Chemical, Physical, and Functional Properties. Advances in Food and Nutrition Research, 33, 343-438. http://dx.doi.org/10.1016/S1043-4526(08)60130-8

[11] Haque, Z.U. and Kinsella, J.E. (1988) Emulsifying Properties of Food Proteins: Bovine Serum Albumin. Journal of Food Science, 53, 416-420. http://dx.doi.org/10.1111/j.1365-2621.1988.tb07719.x

[12] Haque, Z.U. and Kinsella, J.E. (1989) Relative Emulsifying Activity of Bovine Serum Albumin and Casein as Assessed by Three Different Methods. Journal of Food Science, 54, 1341-1344. http://dx.doi.org/10.1111/j.1365-2621.1989.tb05987.x 
[13] Van Oss, C.J., Good, R.J. and Chaudhury, M.K. (1986) The Role of van der Waals Forces and Hydrogen Bonds in "Hydrophobic Interactions" between Biopolymers and Low Energy Surfaces. Journal of Colloid and Interface Science, 111, 378-390. http://www.sciencedirect.com/science/article/pii/002197978690041X http://dx.doi.org/10.1016/0021-9797(86)90041-X

[14] Van Oss, C.J., Absolom, D.R. and Neumann, A.W. (1979) Repulsive van der Waals Forces. II. Mechanism of Hydrophobic Chromatography. Separation Science and Technology, 14, 305-317. http://dx.doi.org/10.1080/01496397908057149

[15] Petersen, R.G. (1985) Design and Analysis of Experiments. Marcel Dekker, Inc., New York.

[16] Anonymous (1985) SAS/STAT Guide for Personal Computers. 6th Edition, SAS Institute, Cary.

[17] Student (1908) The Probable Error of a Mean. Biometrika, 6, 1-25.

[18] Franks, F. and Franks, F. (1972) Introduction-Water, the Unique Chemical. In: Franks, F., Ed., The Physics and Physical Chemistry of Water, Water: A Comprehensive Treatise, Vol. 1, Plenum Press, New York, 1-20. http://dx.doi.org/10.1007/978-1-4684-8334-5_1

[19] Franks, F. (1973) Water: A Comprehensive Treatise, Vol. 3. Aqueous Solutions of Simple Electrolytes. Plenum Press, New York. http://dx.doi.org/10.1007/978-1-4684-2955-8

[20] Franks, F. (1975) Water: A Comprehensive Treatise, Vol. 4. Aqueous Solutions of Amphiphiles and Macromolecules. Plenum Press, New York. http://dx.doi.org/10.1007/978-1-4684-2958-9

[21] Tanford, C. (1970) Protein Denaturation: Part C.* Theoretical Models for the Mechanism of Denaturation. Advances in Protein Chemistry, 24, 1-95. http://dx.doi.org/10.1016/S0065-3233(08)60241-7

[22] Bernal, V. and Jelen, P. (1985) Thermal Stability of Whey Proteins-A Calorimetric Study. Journal of Dairy Science, 68, 2847-2852. http://dx.doi.org/10.3168/jds.S0022-0302(85)81177-2

[23] Telo da Gama, M.M. and Gubbins, K.E. (1986) Adsorption and Orientation of Amphiphilic Molecules at a Liquid-Liquid Interface. Molecular Physics, 59, 227-239. http://dx.doi.org/10.1080/00268978600102031

[24] Tadros, T. (1988) Aspects of Emulsions and Dispersions. Part 1. Informations Chimie, 293, 159-165.

[25] Walstra, P. (1987) Overview of Emulsions and Foam Stability. In: Dickinson, E., Ed., Food Emulsions and Foams, Proceedings of International Symposium, Leeds, 24-26 March 1986, The Royal Society of Chemistry, London, $242-$ 257.

[26] Damodaran, S. and Rao, C.S. (2001) Molecular Basis of Protein Adsorption at Fluid-Fluid Interfaces. Special Publication-Royal Society of Chemistry, No. 258, 165-180. 